\title{
A infância de João Guimarães Rosa: biografia para crianças e literatura para jovens leitores, nasceiro e torrente
}

\author{
The childhood of João Guimarães Rosa: the biography for children and the literature for young readers, \\ headwater and water flow
}

\section{Fabiano Tadeu Grazioli}

Universidade Regional Integrada do Alto Uruguai e das Missões - URI - Erechim - Rio Grande do Sul - Brasil

\section{Alexandre Leidens}

Universidade Tecnológica Federal do Paraná - UTFPR - Pato Branco - Paraná - Brasil

\section{Tânia Mariza Kuchenbecker Rösing}

Universidade de Passo Fundo - UPF - Passo Fundo - Rio Grande do Sul - Brasil

\begin{abstract}
Resumo: A infância e a vida adulta de João Guimarães Rosa já ganharam as páginas de biografias, memórias e estudos que evidenciam a sua genialidade e, por vezes, ultrapassam o aspecto formal das biografias para o leitor adulto, transformando-se em obras específicas para o público infantil e juvenil. "João, o menino Rosa", de Lúcia Fidalgo (2011), e "João, Joãozinho, Joãozito: o menino encantado", de Claudio Fragata (2016), são exemplos dessas ocorrências. A primeira é uma biografia para crianças e a segunda é uma obra literária juvenil inspirada na vida, sobretudo na infância de João Guimarães Rosa. Este artigo, resultante de pesquisa qualitativa de natureza aplicada, procura perceber em que medida os dois autores contemporâneos se colocam em diálogo com algumas publicações de teor memorialístico sobre o autor mineiro. Não se pretendeu refazer o itinerário de pesquisa dos dois autores, embora tenha sido inevitável embarcar nos seus percursos criativos para concluir que, nas suas elaborações, as reminiscências da vida do autor mineiro evidenciadas nas memórias de seu tio, sua filha e de especialistas, estão pulsantes, à espera do leitor infantil e juvenil. Assim, a vida de João Guimarães Rosa não constitui um círculo fechado e intocável, e é nesse sentido que o exercício que se realiza aponta para o aproveitamento de suas memórias na composição da escrita para crianças e jovens na atualidade.
\end{abstract}

Palavras-chave: João Guimarães Rosa; memória; escritas contemporâneas.

Abstract: The childhood and the adult life of João Guimarães Rosa are on the pages of biographies, memories and studies that evidence his genius and sometimes go beyond the formal biographies for adult readers. Thus, these books were written especially for infant and juvenile public. "João, o menino Rosa" written by Lúcia Fidalgo (2011), and "João, Joãozinho, Joãozito: o menino encantado" written by Claudio Fragata (2016), are good examples of it. The first book is a biography for children and the second one is a juvenile literary book inspired by the life, childhood and the work of João Guimarães Rosa. This article is based on a qualitative research that tries to understand to what extent the two contemporary authors are placed in the dialogue with some memorialistic content of publications about the author. It was not intended to remake the itinerary research of the two authors but it was inevitable to embark on his creative paths to conclude that all the elements of his work are waiting for the infant and juvenile readers, like: the elaborations, the reminiscences of the author's life evidenced in his uncle's, his daughter's and experts' memories. These memories are pulsating, waiting for the infant and juvenil reader. Thus, the life of João Guimarães Rosa does not constitute a closed and untouchable circle. In this case, the carried out exercise points to the use of his memories for writing composition for children and young people today.

Keywords: João Guimarães Rosa; memory; contemporary writing 


\section{Proemio ou introito}

A obra de João Guimarães Rosa é estudada por inúmeras razões, suas propriedades literárias ficam evidentes em qualquer leitura atenta que se faça de seus textos. Para além das histórias e tramas que se desenham ininterruptamente, abraçando a perspectiva do regionalismo já assistido no país e historicamente retratado - acrescentando, ainda, o teor psicológico, efervescente no seu tempo -, o autor absorve inúmeras possibilidades linguísticas dentro do âmbito regional e inclui neologismos construídos com precisão e perspicácia.

Não apenas por isso, a obra de Guimarães Rosa tem uma fortuna crítica múltipla e vasta, tamanhas são suas peculiaridades e traços característicos, bem como por sua complexidade e amplitude. De um modo ou outro, é natural que o interesse por um autor tão singular na literatura brasileira ultrapasse sua obra e adentre à sua vida, que, como a de cada ser humano, é também singular. A infância e a vida adulta do autor ganharam as páginas de várias biografias, memórias e estudos outros que evidenciam a sua genialidade e, por vezes, ultrapassam o aspecto formal das biografias para o leitor adulto e se transformam, inclusive, em obras específicas para o público infantil e juvenil.

São os casos de "João, o menino Rosa", de Lúcia Fidalgo (2011) e "João, Joãozinho, Joãozito: o menino encantado", de Claudio Fragata (2016). O primeiro é uma biografia para crianças produzida para a Coleção "Brasileirinhos", que se propõe a apresentar algumas personalidades paradigmáticas do país, de maneira que sirvam de inspiração e estímulo para iniciantes em leitura, dirigida, em especial, ao público infantil. Fragata (2016), por sua vez, constrói um livro literário juvenil, que aborda aspectos biográficos ligados, principalmente, à infância de Guimarães Rosa, baseado em biografias e livros memorialísticos, além de, assim como Fidalgo (2011), subsidiar-se na produção literária do autor.

Fidalgo (2011) expõe aspectos da vida e da obra de Guimarães Rosa de modo sutil e amplo, obedecendo à proposta da Coleção "Brasileirinhos".
Fragata (2016) compõe um livro literário juvenil, em que o enredo é baseado em parte da biografia, sobretudo da infância de Guimarães Rosa. O objetivo deste trabalho é levantar alguns aspectos da infância de Rosa, elencados por esses dois autores, que encontram correspondência em publicações sobre a sua vida, como as memórias do seu tio e de sua filha mais velha, entre outras publicações de natureza biográfica. Não se pretende refazer ou percorrer 0 itinerário de pesquisa de Fidalgo (2011), que resultou na elaboração da biografia para crianças apresentada no livro em questão, nem o caminho percorrido por Fragata (2016) na concepção de sua obra literária juvenil, mas sim mobilizar conhecimentos importantes sobre a vida de Rosa, encontradas em publicações de teor memorialístico para os quais as obras de Lúcia Fidalgo e Claudio Fragata abrem passagem. Os leitores infantis e juvenis que, no presente, conhecem as duas obras em questão, têm uma experiência importante na sua recepção, mas também podem ser os leitores que, no futuro, entrarão em contato com o universo roseano, ou seja, com sua produção artística e com aspectos de sua vida trazidos à luz pelas memórias familiares, num processo contínuo e gradativo de crescimento e amadurecimento, haja vista a importância de se conhecer a literatura, a fortuna crítica e a memorialística daquele que é considerado um dos mais importantes escritores brasileiros. O estudo, empreendido por meio do artigo ora proposto, possui abordagem qualitativa, sendo de natureza aplicada; o procedimento técnico envolve pesquisa bibliográfica e documental, partindo de conhecimentos já produzidos e explorando materiais que não receberam tratamento analítico.

As biografias escolhidas para o trabalho são "Joãozito: a infância de João Guimarães Rosa" (2006), de autoria de Vicente Guimarães, tio do autor mineiro; "Relembramentos: João Guimarães Rosa, meu pai" (2008), de autoria de Vilma Guimarães Rosa, filha de Rosa; e "Veredas de Viator", de autoria de Ana Luiza Martins Costa, especialista em Guimarães Rosa, material que se encontra no número cinquenta dos "Cadernos de Literatura Brasileira" (2006), número este dedicado a João 
Guimarães Rosa, publicado pelo Instituto Moreira Salles. Acreditamos ser este um número de publicações adequado para o trabalho a ser realizado e que a natureza diversa das biografias (a do tio amigo de infância, a da filha e a da especialista) contribui para a apreensão dos pontos de vista dos dois livros, a partir dos quais o estudo emerge.

\section{Da Meninez, em Cordisburgo: leitura, animais e miopia}

Você não deveria me pedir mais dados numéricos. Minha biografia, sobretudo minha biografia literária, não deveria ser crucificada em anos. As aventuras não têm tempo, não têm princípio nem fim.

Guimarães Rosa, em entrevista a Günter Lorenz.

Considerando as duas obras, uma para crianças e outra para jovens leitores, as quais serão observadas à luz das biografias e estudos publicados sobre Guimarães Rosa, já mencionados, convém adiantar que a cronologia dos acontecimentos biográficos e as tramas não serão demarcadas e nem servirão como preceitos para a ordenação dos aspectos contidos no trabalho, ao gosto de Guimarães Rosa, como se nota na epígrafe, a não ser a pequena sinalização que se fez nos títulos, apontando o nome das duas cidades que envolvem a infância do escritor; tampouco serão levantados critérios de valoração sobre a criação artística de Fidalgo (2011) e Fragata (2016).

As duas obras abordam o ambiente familiar, seus autores ilustram-no na pequena Cordisburgo, cidade mineira, onde nasceu Guimarães Rosa. Sem ser o epicentro dos acontecimentos, há referências à cidade na obra "João, o menino Rosa", ao passo que, no tangente à família, há uma breve descrição dos pais: a mãe aparentando ternura e o pai, lembrado como comerciante, juiz de paz, caçador, contador de histórias e detentor de um nome difícil: Florduardo (FIDALGO, 2011). O nome do pai em "João, Joãozinho, Joãozito" é tido como "perfumoso", mas, por comodidade, virava "seu Fulô", pai de uma família de seis filhos, dos quais João é o mais velho. A mãe e a bisavó são dois opostos, a primeira, branda e benevolente, a segunda, brava, rígida, mas lembrada pelos biscoitos deliciosos que fazia. Cordisburgo é um lugarejo "[...] tão de repente bonito" (FRAGATA, 2016, p. 6), dessa forma se refere o autor à cidade, com a mesma frase proferida por Guimarães Rosa no discurso de posse na Academia Brasileira de Letras e relembrada por Vicente Guimarães em "Joãozito: a infância de João Guimarães Rosa" (2006, p. 22). O lugar em que viveu os primeiros anos de vida, bem como as relações com as pessoas da família e da comunidade e o contato com animais, domésticos ou não, possibilitaram a curiosidade do menino ser bastante estimulada. A venda do pai, em frente à estação de trem, era um local onde passavam inúmeros viajantes, garimpeiros, fazendeiros, vaqueiros, lavradores e mascates. João, ainda pequeno, do outro lado do balcão, ouvia atentamente as histórias que cada um contava, satisfazendo e intensificando sua curiosidade (FRAGATA, 2016). Costa (2006, p. 11) confirma esses contornos da vida de Rosa, ao salientar que "O menino Joãozito cresce ouvindo estórias contadas pelos frequentadores da venda de seu Fulô".

O jeito reflexivo do garoto fica evidente na biografia para crianças, na qual a cena inicial retrata a mãe levando-o para casa e, com ele, seus pensamentos. A ilustração dá indícios de que o menino não desejava se desvencilhar da sua meditação, por estar olhando para trás enquanto caminha de mão dada à mãe, como se tivesse lá deixado algo ou se despedisse, dizendo nada poder fazer para lá ficar por mais tempo (FIDALGO, 2011). Essa característica é observada nas memórias da infância de Guimarães Rosa escritas pelo tio, apenas dois anos mais velho, com o qual cresceu em Cordisburgo, e com quem manteve amizade e correspondência durante toda a vida. Vicente Guimarães (2006) aponta o menino como diferente por raramente brincar e diz ter sido ele sossegado, calado, calmo, observador e singelo.

A aprendizagem e o exercício da leitura talvez sejam os maiores acontecimentos da infância de Guimarães Rosa. Na obra de Fidalgo (2011), é 
possível observar a escola como um local de incentivo e propulsão de suas características criativas e reflexivas, o que vai ao encontro da sua curiosidade pelas palavras, contos e histórias e pela natureza, sobretudo, pelos animais. Fragata (2016) oferece uma visão da leitura como uma grande descoberta, de imprescindível valor e causadora de felicidade para o menino, que a aprendeu antes mesmo de chegar à escola e, quando nela se encontrou, já lia com desenvoltura os livros indicados para sua idade, de maneira que "[...] o velho professor não viu outro jeito senão dar livros mais difíceis àquele pirralho que nem sete anos tinha ainda" (FRAGATA, 2016, p. 14). A mãe do menino, inclusive, reconhecia sua sede de saber. "Joãozito era um menino sábio [...]. Aprendeu a ler e a escrever muito cedo, para saciar a sua intensa curiosidade de conhecimentos". (ROSA, 2008, p. 39). Os livros se tornaram a sua obsessão, dedicava praticamente todo o tempo e atenção a eles, desligando-se do mundo e fazendo de tudo para conseguir ler. Mesmo quando descobriu a miopia e ficou sujeito à orientação médica de diminuir a leitura para não forçar os olhos, escondia-se onde podia para esse fim.

Um dia, Joãozito sumiu. Procura que procura e nada. Cadê esse menino, meu Deus? Ninguém viu, ninguém dele sabia. Deu a hora do almoço e seu lugar ali vazio na mesa. Mas ninguém tinha fome. Dona Chiquitinha rezou todas as rezas que sabia e agora o que podia era chorar. Todas as mulheres vieram dar consolo. Os homens se espalharam pelas ruas, pelos matos, subiram morros, nalgum lugar Joãozito havia de estar. Nenhuma pista. Horas mais tarde, foram voltando eles, vergonhosos de tanta incapacidade de encontrar menino sumido. (FRAGATA, 2016, p.18)

Não se sabia onde ele estava e somente no final da tarde, quando um funcionário de seu pai precisou ir até o depósito pegar mercadorias é que foi achado, lá, trancado e adormecido, ao lado de um toco de vela, duas varetinhas e um livro aberto em seu colo (FRAGATA, 2016). Essa é uma história peculiar da infância de Guimarães Rosa, que ilustra o seu devotamento pela leitura e é citada da mesma forma também em Guimarães (2006) e em Rosa (2008), que diz serem comuns as escapadas do menino para ler. Não obstante,
Dessa vez, foram procurá-lo nos lugares de sempre: nas cisternas, no Ribeirão da Onça, perto do Pontilhão onde se banhavam os meninos. A noite subia. E nada de Joãozito. Afinal, o encontraram nos fundos da loja, no depósito de mercadorias, adormecido sobre um saco de arroz. Nas mãos, um livro. Ao lado, quase acabada de queimar, uma vela ainda acesa. (ROSA, 2008, p. 94).

Para além disso, era "Madrugador, costumava Joãozito levantar-se no entreluz da aurora, escuro ainda, e ler à luz da vela, até o sol iluminar. Mais tarde, sempre naquela gozosa tranquila atividade sua, justo de novo tivesse sono". (GUIMARÃES, 2006, p. 29).

Das poucas coisas que o desligavam da leitura, o contato com os animais era a mais frequente. Em Cordisburgo, não apenas ele, mas o povo todo assistia a um espetáculo que acontecia em frente à sua casa, na estação de trem: o embarque de bois. João observava atento e "[...] se despedia deles com um nó na garganta como se fossem velhos amigos indo embora. Eram mesmo. Joãozito amava os bois profundamente. Tinha certeza de que eles sabiam falar e conversavam entre si. Que o pensamento dos bois era grande e quieto". (FRAGATA, 2016, p. 8). O próprio Guimarães Rosa relata sua predileção por gatos e bois em conversas e entrevistas (ROSA, 2008). Pode-se sugerir que, com o devaneio e o deslumbramento da observação dos bois, ocorrido, sobretudo na infância, Guimarães Rosa constrói outras perspectivas na literatura que abordam a relação do homem com o animal, sem considerar o mundo do animal como diferente ou alheio, mas como se as duas esferas se tocassem e desvencilhassem aos poucos, paulatinamente, convergindo e se retraindo, de acordo com o momento. $\mathrm{O}$ animal consegue perceber e analisar da sua forma a vida humana e o humano que, aparentemente, não lhe dá tanto valor e carrega características, inclusive, animalescas. Na relação do homem com o animal, é ultrapassada a relação primeira que se detém na supremacia do homem, como se este fosse o todo poderoso e soubesse de tudo, chegando-se a uma visão mais terna, mas não menos crítica, em uma perspectiva na qual os animais são antropomorfizados, tendo, assim, visão e 
sentimento, diálogo e ação, princípios e filosofia. Clarissa Moreira de Macedo (2013), em sua dissertação de Mestrado, avaliou a característica do antropomorfismo nos contos de Guimarães Rosa e Miguel Torga. Ela confirma, em seu trabalho, que no conto "Conversa de Bois", parte de "Sagarana", predomina o que podemos considerar uma atmosfera filosófica entre os bois, atmosfera essa que pouco se altera ou modifica e que se torna responsável pela forma de os bois agirem e pensarem na trama, o que influencia sua índole.

\begin{abstract}
O trajeto galgado pelos bois na narrativa é filosófico porque constitui uma busca, uma indagação pelo sentido das coisas presentes no mundo, sobretudo no plano do indizível. É filosófico também porque procura pela decifração dos enigmas que permeiam a existência, processada entre a materialização e a sublimação do plano concreto, questionando as certezas estabelecidas e instaurando o absurdo e o enigmático no seio da experiência do real. (MACEDO, 2013, p. 94).
\end{abstract}

A autora caracteriza a trajetória vivida pelos bois como mística e instintiva. Tudo isso somado aos acontecimentos da trama levam a crer que os animais são sensatos, neutros e legítimos, se comparados aos seres humanos. Há um aspecto implícito nesse contexto que caracteriza homem e animal: o homem é cruel, maldoso, insensato, diferentemente dos animais, que são bondosos e equilibrados. No conto em questão, os bois manifestam um poder reflexivo e um senso de justiça bastante desenvolvido. "Longe de uma visão maniqueísta e de julgamentos que qualifiquem a morte de um homem como uma decisão eticamente correta, o que é apresentado no conto é o modo como os bois percebem e interpretam a vida e seu ciclo básico, que é o de nascer, crescer e morrer". (MACEDO, 2013, p. 93).

No conto, são os bois que decidem pelo destino tomado e pela vida do menino personagem, delegando ao seu opressor a morte. Eles traçam um itinerário filosófico, buscam um sentido nas coisas do mundo, querendo descodificar esses enigmas, até certo ponto, esquecidos pelo homem. Entretanto, não só nesse conto aparecem os animais na obra de Guimarães Rosa. Antropomorfizados ou não, em muitas outras escritas são os animais, os personagens mais enigmáticos e especiais das tramas.

Embora sua ligação com os bois se sobressaísse, o menino amava os animais, em geral, de maneira que não concordava com uma das atividades preferidas do pai: a caça. A única vez em que foram juntos caçar, espantou, com um grito, um veado que apareceu enquanto o pai cochilava, escorado em uma árvore (FRAGATA, 2016). "Joãozito precisou disfarçar a alegria para não fazer desfeita ao pai. Deus o livre de ver o bichinho morto. Depois disso, nunca mais na vida foi a uma caçada". (FRAGATA, 2016, p. 36). O tio, em “Joãozito", faz alusão a essa caçada e termina com a satisfação de João em ver que o pequeno animal conseguiu sobreviver. "Em casa, contando à mãe, sem que o pai ouvisse, afirmou ter ficado satisfeito com a fuga do veado. Muito teria sofrido se visse o pai matá-lo". (GUIMARÃES, 2006, p. 33).

A grande afeição pelos animais era também vista, quando algum animal com o qual tinha relação morria, momento em que o garoto ficava inconsolável. Para ele era uma grande perda. Um caso bastante significativo foi a morte do casal de micos-estrela que andavam pela casa e faziam sua alegria. $O$ menino se perguntava, inconsolável, se devia mesmo Deus deixar morrer criaturas tão graciosas. (FRAGATA, 2016). Menção a essa passagem faz Guimarães (2016), lembrando, como Fragata, a morte da micoestrela, ocorrida por um descuido da empregada ao passar roupas e que culminou com a morte do seu companheiro, morrendo o casal com poucos dias de diferença. "As crianças e Joãozito mais, lamentaram em lágrimas, inconformadas. [...] Morreu de amor e de saudade". (GUIMARÃES, 2016, p. 37).

\section{Frei Canísio, agulhão no estudo de novos idiomas, partida e vida em Belo Horizonte}

À venda de "seu Fulô" chegavam as mais variadas coisas e, em certa ocasião, chegaram algumas revistas muito coloridas que traziam 
reportagens sobre tigres, elefantes, baleias e avesdo-paraíso. A curiosidade de João foi grande e quis logo começar a ler; entretanto, pela primeira vez, "[...] não conseguiu entender o escrito, tudo estava em língua estrangeira: as revistas eram francesas". (FRAGATA, 2016, p. 14). Na ânsia de entender o que estava lá escrito, João tenta de todo modo pedir às diferentes pessoas que circulam pela venda e pela escola. Ninguém pode ajudar, pois não há, na pequena Cordisburgo, quem conheça o idioma. "Por sorte, um viajante e compadre de seu Fulô, comovido com o querer saber de Joãozito, presenteou o menino com uma gramática e um dicionário da língua francesa trazidos da cidade grande". (FRAGATA, 2016, p. 14). O autor apresenta, dessa forma, um dos benefícios que a venda do pai trazia ao menino: o contato com as mais diferentes pessoas, o que permitia a ele conseguir informações, histórias e até materiais, como no caso da gramática e do dicionário, aos quais não tinha acesso na pequena cidade onde nasceu e que não cobria sua incessante curiosidade pelo saber, pelo descobrir, pelo buscar novas informações e leituras.

Tudo melhorou ainda mais com a chegada de Frei Canísio a Cordisburgo. Não era só a missa que o santo homem ajudava a rezar. Com ele, Joãozito aprendeu todo o francês que precisava. Aprendeu também a ler em holandês porque na Holanda o Frei havia nascido. Não demorou para que o aluninho sabido mergulhasse em livros escritos nessas línguas. (FRAGATA, 2016, p. 14).

O Frei é apresentado ao leitor juvenil como um tutor intelectual, com o qual podia o futuro diplomata discutir e conversar sobre os mais variados assuntos, aprender coisas impensáveis para sua época e local de nascimento e se tornar um grande estudioso, mesmo tendo ainda menos de 10 anos. Essas características e a propensão por descobrir coisas novas, a partir ou não da leitura, o tornam um menino único, com particularidades não vistas naquela terra. Da mesma forma, sua maneira de ler era também diferente. "O jeito de Joãozito ler era só dele, só. Cruzava as pernas tal e qual um pequeno Buda, o livro aberto no colo, ia marcando o ritmo da leitura batendo nas páginas com dois pauzinhos, um em cada mão". (FRAGATA, 2016, p. 16). Quando não eram pauzinhos, suas batidas se davam com canudos ou ainda com os próprios dedos indicadores. Fragata (2016, p. 16) relembra a visão da família, achando aquilo uma mania do garoto: "O corpo dobrado, o nariz quase enfiado no livro. Todo mundo na casa estava acostumado com aquele taquetataque-taque, nem estranhava mais esse modo de Joãozito ler. Sabiam que era maniazinha dele".

Costa (2006, p. 12) também alude a essa peculiaridade:

Gostava de sentar no chão com as pernas cruzadas, inclinado sobre um livro aberto no colo, e ficava ritmando a leitura batendo sobre as páginas com dois pauzinhos (ou pedacinhos de papel enrolados como canudos), ora um, ora outro, compassadamente - um hábito de leitura ritmada que nunca abandonou.

Essa característica última demonstra ainda a miopia de João, que foi descoberta com a ida de um médico de Curvelo até sua casa. Quando ele viu o menino tão curvado lendo, desconfiou e, em seguida, ao colocar os seus óculos em João, teve certeza: o menino era míope e, enquanto não lhe fosse arrumado um par de óculos, nada de leituras nem nada que forçasse os olhos demais (FRAGATA, 2016).

Joãozito preferia qualquer outro castigo, ficar longe dos livros era para ele o mesmo que não respirar. Passou a ler escondido atrás das portas, nos cantos mais cantinhos do quintal ou de madrugada antes de qualquer um se levantar. Acendia um cotoco de vela e sob a chama bailarinazinha lia até os olhos pesarem de tanto sono. (FRAGATA, 2016, p. 17).

Guimarães (2006, p. 30) relembra que nem por indicação médica Joãozito pararia de ler: "Aí é que o Joãozito se escondia mais, para ler desvisto, principalmente do pai. Só em Belo Horizonte, aos nove anos, começou a usar óculos".

A inventividade e a imaginação são aspectos esperados em todas as crianças. Em Guimarães Rosa, todavia, essas características se potencializavam, de maneira que a biografia para crianças e a obra literária abordam esses pontos com algumas particularidades. Fidalgo (2011) deixa implícito por todo o seu texto que o menino João é 
imaginativo e reflexivo, ao passo que Fragata (2016) insere, inclusive, um romance inventado pelo garoto, sobretudo a partir do estudo e conhecimento da Geografia, quando pediu ao padrinho como presente uma edição de Geografia Lacerda, a qual observava e estudava com afinco.

Desde menino, muito pequeno, eu brincava de imaginar intermináveis estórias, verdadeiros romances; quando comecei a estudar Geografia - matéria que sempre gostei - colocava as personagens e cenas nas mais variadas cidades e países; um faroleiro, na Grécia, que namorava uma moça no Japão, fugiam para a Noruega, depois iam passear no México. (GUIMARÃ̃ES, 2006, p. 39).

O excerto anterior, parte de uma carta enviada para uma prima, estudante, que o entrevistava, também é encontrado em Costa (2006). Revela-se, aí, um João inventor, que vai do Norte ao Sul e busca as mais diversas referências cabíveis ao seu conhecimento para construir seus enredos, suas narrativas e suas tramas. Buscava, por meio da Geografia, entender o mundo em que vivia; muitas das pessoas do lugar não tinham acesso a esse conhecimento ou pouco sabiam do seu entorno. João, ao contrário dos meninos em geral, que apenas supunham o que fosse uma guerra, a observava atentamente.

\begin{abstract}
Anos depois, começou outro divertimento com Frei Canísio. Eram tempos de bombas e destruição da Primeira Guerra Mundial. Abriam eles o mapa da Europa sobre a mesa e com alfinetes espetavam os avanços e os recuos das tropas alemãs e dos exércitos aliados. Torciam ambos pela vitória dos aliados. Joãozito chegava a pensar em triunfantes estratégias. Ah, se seus planos chegassem às mãos dos generais! Imaginar um fim para a guerra era tão bom quanto inventar histórias, coisa que ele não conseguia parar de fazer de jeito nenhum. (FRAGATA, 2016, p. 20).
\end{abstract}

Sem dúvida, a influência de Frei Canísio nos estudos de João foi grande, não apenas no que toca ao conhecimento geográfico, mas também na formação cultural geral e no estudo de outros idiomas, já que, além do francês - que o menino já começara a estudar -, o Frei também conhecida o holandês, e, nesse idioma, João leria muitas obras a partir de então. As estratégias de guerra, no entanto, foram uma primeira ligação entre os dois.

Acompanhavam e comentavam ambos, entusiasmados, o desenrolar da Primeira Grande Guerra Mundial. Estendiam o mapa na mesa e, com alfinetes de cabecinha de cores: vermelho, azul, amarelo, branco e preto [...] marcavam os avanços e recuos das tropas alemãs e das dos aliados, de acordo com o noticiário dos jornais. (GUIMARÃES, 2006, p. 40).

O tema da guerra empolgava a ambos. Rosa (2008, p. 42) ainda complementa, enaltecendo a sugestão e o acerto do pequeno João: "Certa vez, Joãozito sugeriu que se os Aliados agissem de forma tal, certamente ganhariam a batalha. $E$ foi o que aconteceu. Isto, de certa forma, celebrizou-o entre os mestres e os colegas. Alguns padres redentoristas fizeram questão de conhecê-lo pessoalmente".

Não apenas pela Geografia ele se interessava, mas pelas características de cada lugar, sua cultura, seu povo e, inclusive, seus animais. Esses, como já dito, foram uma paixão do menino, não apenas brincava com eles, mas também os observava atentamente e os estudava. "O interesse de Joãozito pelos bichos era tão grande que o menino queria saber tudo a respeito deles. Estudava biologia para aprender mais sobre o mundo animal. Tinha em casa um laboratório de insetos vivos e mortos". (FRAGATA, 2016, p. 28). Além disso, toda vez que encontrava algum inseto morto pelo chão, abria seu corpo com um canivete para observá-lo, deixando as sobras em um formigueiro para que se transformassem em um banquete para as formigas (FRAGATA, 2016). Esse gosto pelos animais o fez ficar responsável pelo museu de insetos vivos e mortos da Escola Mestre Candinho, que contava com joaninhas, grilos, cigarras, besouros e muitos outros. (GUIMARÃES, 2006, p. 44).

De fato, seja como pequeno cientista ou como amante inveterado das palavras, das narrativas, do estudo e dos livros, o garoto era um prodígio na escola, e a biografia para crianças, mesmo não se atendo aos acontecimentos e peripécias escolares realizadas por ele, deixa claro ser muito profícuo no 
estudo o menino (FIDALGO, 2011). "Espalhou-se a sua fama de inteligente e estudioso. Sua prodigiosa memória comentada era, e seu saber de criança, respeitado". (GUIMARÃES, 2006, p. 44).

Não sem emoção ocorreu a mudança de João para Belo Horizonte, com menos de nove anos. Sua fome de saber fazia da pequena cidade uma ilha para ele.

De repente, Cordisburgo ficou muito pequena para a vontade grande de saber e aprender de Joãozito. Ele então foi morar com os avós em Belo Horizonte, onde havia boas escolas e até... bibliotecas! O garoto não via a hora de entrar numa delas e ficar cercado de livros por todos os lados. (FRAGATA, 2016, p. 29).

A ida de João para Belo Horizonte foi percebida como uma aposta do avô, que lá morava, esperando apresentar ao menino um ambiente cultural e educacional maior e mais frutífero é apresentada por Guimarães (2016, p. 47): "Menino inteligente, realçado do comum, nele viu o avô a necessidade de melhores possibilidades intelectuais. Em sua casa, na capital mineira, viver poderia 0 estudante em contato com pessoas mais cultas e facilidades outras obteria para ampliar o aprendizado".

Dois são os casos curiosos acontecidos com João em Belo Horizonte e relembrados na obra de Fragata (2016). O primeiro deles é o piquenique na biblioteca. Todo domingo, João ia à biblioteca, lá passava as tardes lendo tudo o que podia e tinha, inclusive, um lugar preferido, longe de ruídos e conversas que, por ventura, poderiam atrapalhá-lo. Antes de ir até lá, parava para comprar seu lanche, que era composto por pastéis, empadas de camarão e um refrigerante. Comia tudo isso enquanto lia na biblioteca. Um usuário ficou revoltado com a audácia do menino em comer e engordurar os livros dentro da própria biblioteca (FRAGATA, 2016).

O bibliotecário tentou acalmar o homem chato e implicante dizendo que Joãozito vinha sempre à biblioteca. Que o garoto tinha uma grande paixão pelos livros e tomava sempre o maior cuidado para não estragar nenhum deles. Que era assombroso como ele lia com prazer e entendimento livros que não tinham sido escritos para leitores de sua idade.
Não satisfeito, o homem se aproximou e espichou o pescoço sobre os ombros do menino para ver o que ele estava lendo. $O$ homem chato e implicante é que ficou com cara de pastel: Joãozito estava lendo um clássico da literatura francesa. (FRAGATA, 2016, p. 30).

Em "Joãozito", o autor retrata esse acontecimento incluindo as falas do frequentador e do funcionário. "Não tenha receio - tranquilizou-o o funcionário - ele é assíduo frequentador da biblioteca e, aos domingos, sempre passa a tarde toda aqui, onde faz o lanche, lendo sem perda de um minuto. Dê um pulo, desapercebido, até lá e, cauteloso, veja e anote o que ele está lendo". (GUIMARÃES, 2006, p. 51). “Joãozito, tranquilamente, estava lendo um clássico francês. Este caso, contado a todos pelo bibliotecário, se tornou o assunto da família e dos amigos". (ROSA, 2008, p. 41). A visita à biblioteca para devorar livros, sempre ocorrida nos domingos, é tida, de acordo com Costa (2006), como um refúgio.

O segundo episódio acontecido em Belo Horizonte que chama atenção é o de João estar lendo na varanda da casa dos avós e observar um senhor japonês da companhia de eletricidade trabalhando em um poste. João esperou que descesse e fez várias perguntas, sobretudo sobre como eram os cumprimentos em japonês. No dia seguinte, demonstrou ao mesmo homem que se lembrava de tudo o que havia pedido e ainda agradeceu em japonês. "O funcionário ficou tão espantado com o interesse de Joãozito que passou a dar aulas diárias ao garoto. Esse foi o começo de seu estudo do idioma japonês, que depois ele aprofundou sozinho". (FRAGATA, 2016, p. 31). Guimarães (2006) relembra o ocorrido com agrado e benevolência, de maneira que é esse apenas mais um dos capítulos de uma grande história de curiosidades e aprendizado do futuro escritor.

\section{Algumas palavras sobre oralidade, memória e o remate}

Não apenas com as obras biográficas ou estudos teóricos, mas também na leitura da obra literária de Guimarães Rosa, percebe-se que utilizava 
ele muitos aforismos, elementos e características da cultura popular do sertão, baseando-se constantemente na sua própria experiência de vida ou em experiências e casos alheios, que lhe chegavam das mais variadas formas. A essa contingência de acontecimentos e histórias, dava ele uma centelha de trabalho literário, buscando entregar à memória mais tempo, aos acontecimentos do sertão mais amplitude e perenidade, aos homens reais, sofridos e contemporâneos, de sua terra, mesmo que parcialmente, mais memória e vida, uma vida outra que não se termina, que se renova, se transmuta e completa com cada leitura, com cada verso, com cada fala, com cada conto. Assim tirava Guimarães Rosa os sertanejos tradicionais e peculiares da vastidão do esquecimento, dando-lhes voz, vez e reminiscência.

O autor baseava-se, sobretudo, na história oral de seu povo, de tal maneira que ela enseja toda essa perspectiva de não esquecimento e sobrevivência aos contos e relatos sertanejos que ganham uma sobrevida ou uma existência diferente em Guimarães Rosa. Uma existência literária, que os aproxima de outros indivíduos os quais não poderiam conhecer tais acontecimentos ou contos e que, agora, podem entrar nesse mundo vasto e próximo, que é o dos contos, "causos" e histórias do sertão, pois ele adquiriu longevidade e substância física e material, de modo que todos os homens podem acessá-lo, contínua e frequentemente. Guimarães (2006, p. 112) afirma que "Joãozito aproveitava em literatura o que ouviu em criança, muito sendo recontado por seu pai. Deste, usou também termos diversos.". Ao pai, de fato, é recorrente o pedido para relembrar alguns fatos, pessoas, expressões ou histórias, como nesse fragmento de uma carta:

[...] o que mais me interessa é a história do Juca Ferreira, aquêle que vinha fazendo festas, com a viola, pelo Rio das Velhas, até Pirapama. Lembro-me de que era fazendeiro e tinha tenda de ferreiro, mas mais não sei. Imaginei uma história, tendo-o como personagem, e para isso precisava de saber mais detalhes. Se o senhor se lembrar de alguma coisa a respeito dêle e das suas excursões festivas, mande-me, por favor. Também, sempre que se lembrar de cantigas ou expressões sertanejas legítimas, ouvidas de caipiras nossos, de Cordisburgo ou Gustavo da Silveira. E tudo o que se refira a vacas e bezerros. Estou escrevendo outros livros (ROSA, 2008, p. 242-243).

Ela está, a história oral, indissoluvelmente presente no dia a dia, sobretudo em um ambiente familiar e social próximo, sem haver, geralmente, uma coleta ou catalogação desses contos e "causos", deixando-os à mercê do esquecimento. Justamente essa recuperação, por assim dizer, da memória é o que faz Guimarães Rosa em grande parte de - senão em toda - sua obra literária.

A história oral é uma história construída em torno das pessoas. Ela lança a vida para dentro da própria história e isso alarga seu campo de ação. Admite heróis vindos, não só dentre os líderes, mas dentre a maioria desconhecida do povo [...]. Traz a história para dentro da comunidade e extrai a história de dentro da comunidade. Ajuda aos menos privilegiados, especialmente os idosos, a conquistar dignidade e autoconfiança. Propicia o contato e, pois, a compreensão entre classes sociais e entre gerações. E, para cada um dos historiadores e outros que partilha a mesma interação, ela pode dar sentimentos de pertencer a determinado lugar e determinada época. Em suma, contribui para formar seres humanos mais completos. (THOMPSON, 1998, p. 44).

A história oral dá de beber a memória, alicerça toda uma carga cultural e estimulativa de um povo, constitui um berço de possibilidades pelas quais os homens buscam subsistência de forma contumaz. À memória também se pauta pelo orgulho, pelo brio, pela dignidade, pela honra e pela ufania da comunidade.

No afã de manter vivos todos os percalços que emaranharam conquistas e triunfos - bem como, relatos anedóticos ou ainda pedagógicos, sendo esses, mais histórias que justificam conselhos - 0 homem se mantém, se baseia e subsidia na memória, no vivido, por si ou por outros. Assim, se sente altivo, íntegro e parte de um meio, de uma comunidade, de um bem maior do qual sabe ser apenas parte. Tudo isso está em construção, pois além da história de sua comunidade, constrói sua própria memória, que se juntará à memória de seu entorno e servirá de base para as futuras gerações, em um ciclo que pode se 
perder, se renovar, se reconstituir, mas que apenas quando escrito, é perene, palpável e duradouro.

De fato, a memória é parte constituinte importante e sobressalente não somente na literatura de Guimarães Rosa, mas também nas obras que tratam da sua biografia, ilustrando o seu jeito de viver e as relações com os acontecimentos e percalços do mundo, bem como sua sede de conhecimento e devoção pelo trabalho literário. Nesse sentido, há uma visão memorialística ampliada, pois, ao se analisar a perspectiva da infância de Guimarães Rosa e, por consequência, alguns pontos de sua literatura, se ativa a memória e a história de vida do autor e, ainda, a perpetuação das histórias e "causos" inseridos por ele em suas obras.

$\mathrm{Na}$ perspectiva que assumimos na elaboração deste trabalho, tendo presentes os estudos memorialísticos produzidos em torno do autor João Guimarães Rosa, nosso trabalho consistiu em devolver o autor e suas memórias a seus leitores e estudiosos, no sentido de realizar o exercício aqui proposto: o de verificar nas fontes memorialísticas o nasceiro e a torrente do material que hoje se transforma em biografia para crianças e jovens, numa dinâmica constante de recriação empreendida pelos artistas contemporâneos.

A criação literária deste escritor mineiro inconfundível emerge principalmente do envolvimento laborioso com a memória e a oralidade, conforme expusemos anteriormente. Parece fundamental registrar que o movimento por nós flagrado neste trabalho seja um indício de que em Rosa, a memória é um elemento balizador na construção poética e um círculo que não se fechou no próprio autor: é também a partir da memória, como demonstraram Fidalgo (2011) e Fragata (2016), que a literatura para crianças e jovens pode se constituir, dando margem ao nascimento de novas obras, com os elementos que a literatura infantil e juvenil contemporânea exigem, em contínuo diálogo com as experiências dos grandes autores.

\section{Referências}

FIDALGO, Lúcia. João, o menino Rosa. Ilustrações: Fabiana Salomão. São Paulo: Paulus, 2011.

FRAGATA, Claudio. João, Joãozinho, Joãozito: o menino encantado. Ilustrações: Simone Matias. Rio de Janeiro: Galerinha Record, 2016.

GUIMARÃES, Vicente. Joãozito: a infância de João Guimarães Rosa. São Paulo: Panda Books, 2006.

COSTA, Ana Luiza Martins. Veredas de Viator. In: JOÃO GUIMARÃES ROSA. Cadernos de Literatura Brasileira, Instituto Moreira Salles, 2006.

LORENZ, Günter. Diálogo com Guimarães Rosa. In: COUTINHO, Eduardo (Org.). Guimarães Rosa. Rio de Janeiro: Civilização Brasileira, 1991. p. 6297.

MACEDO, Clarissa Moreira de. O homem na voz dos bichos: o antropomorfismo em contos de Guimarães Rosa e Miguel Torga. Feira de Santana: UEFS, 2013, 119f. Dissertação (Mestrado em Literatura e Diversidade Cultural) Programa de Pós-Graduação em Literatura e Diversidade Cultural, Universidade Estadual de Feira de Santana, Feira de Santana, 2013.

ROSA, Vilma Guimarães. Relembramentos: João Guimarães Rosa, meu pai. Rio de Janeiro: Nova Fronteira, 2008.

THOMPSON, Paul. A voz do passado: história oral. São Paulo: Paz e Terra, 1998.

\section{COMO CITAR ESSE ARTIGO}

GRAZIOLI, Fabiano Tadeu; LEIDENS, Alexandre; RÖSING, Tânia Mariza Kuchenbecker. A infância de João Guimarães Rosa: biografia para crianças e literatura para jovens leitores, nasceiro e torrente. Signo, Santa Cruz do Sul, v. 42, n. 74, p. 47-56, maio 2017. ISSN 1982-2014. Disponível em: <https://online.unisc.br/seer/index.php/signo/article/view/8560>. Acesso em: doi: http://dx.doi.org/10.17058/signo.v42i74.8560. 